\title{
ACICULAR FERRITE FORMATION IN A MEDIUM CARBON STEEL WITH A TWO STAGE CONTINUOUS COOLING
}

\author{
I. Madariaga*, I. Gutiérrez*, C. García-de Andrés** and C. Capdevila** \\ * Centro de Estudios e Investigaciones Técnicas de Guipúzcoa (CEIT) Po Manuel Lardizabal, 15, \\ 20009 San Sebastián, Basque Country, Spain ** Department of Physical Metallurgy, Centro \\ Nacional de Investigaciones Metalúrgicas (CENIM), Consejo Superior de Investigaciones Científicas \\ (CSIC), Avda. Gregorio del Amo, 8. 28040 Madrid, Spain
}

(Received February 8, 1999)

(Accepted in revised form April 18, 1999)

Keywords: Acicular; Transformations; Inclusions; Intragranular

\section{$\underline{\text { Introduction }}$}

Although acicular ferrite has been usually associated to the low carbon microalloyed steels used in weld deposits (1-4), the development of this kind of microstructure in medium carbon microalloyed forging steels has been recently documented $(5,6)$. Its main interest lies in the good combination of mechanical properties that presents as compared with bainite and above all with ferritic-perlitic microstructures. The major improvement is obtained in toughness, thanks to the fine interlocking microstructure characteristic of acicular ferrite which makes crack propagation difficult due to the presence of a great number of ferrite grain boundaries per unit length (7-12).

It is accepted that nucleation of acicular ferrite takes place inside the austenite grains at non metallic inclusions, whose nature and number can determine the transition from an acicular ferrite microstructure to a bainitic one. In the case of the medium carbon forging steel of the present work, the exact mechanism of actuation of the second phase particles responsible for the nucleation of acicular ferrite has previously been reported (13-16). However, the heat treatments necessary to achieve a high volume fraction of acicular ferrite with continuous cooling have to be studied in order to increase the industrial production and application of this steel. With this purpose, firstly isothermal treatments have been carried out to know the different austenite transformation products that are developed in each range of temperatures, and afterwards continuous cooling transformation diagrams (CCT) have been obtained to determine the cooling rates needed to produce them. As a result, a two stage continuous cooling cycle is proposed as the best heat treatment to produce acicular ferrite with a low volume fraction of other phases such as alotriomorphic ferrite, pearlite, and/or martensite.

\section{Experimental Procedure}

The chemical composition of the steel used in the present work is shown in Table 1. Dilatometric experiments, directed towards the determination of the previous austenite grain size (PAGS) and to resolve the CCT curves, were carried out in a high resolution dilatometer DT1000 Adamel-Lhomargy 
TABLE 1

Chemical Composition of Microalloyed Steel (Weight Percent)

\begin{tabular}{|c|c|c|c|c|c|c|c|c|c|c|c|}
\hline $\mathrm{C}$ & $\mathrm{Mn}$ & $\mathrm{Si}$ & $P$ & $S$ & $\mathrm{Cr}$ & Mo & $\mathrm{V}$ & $\mathrm{Cu}$ & $\mathrm{Al}$ & $\mathrm{Ti}$ & $\mathrm{N}$ \\
\hline 0.37 & 1.45 & 0.56 & 0.01 & 0.043 & 0.04 & 0.025 & 0.11 & 0.14 & 0.024 & 0.015 & 0.0162 \\
\hline
\end{tabular}

using rod samples of 2-mm thick and 12-mm long. These samples were austenitized for 60 seconds at $1200^{\circ} \mathrm{C}(\mathrm{PAGS}=66 \mu \mathrm{m})$ and immediately cooled at different rates between $100^{\circ} \mathrm{C} / \mathrm{s}$ and $0.5^{\circ} \mathrm{C} / \mathrm{s}$.

Isothermal treatments were conducted in cubic samples of $10 \mathrm{~mm}$ side austenitized in an inert argon atmosphere followed by direct quenching into a salt bath at different temperatures ranging from $600^{\circ} \mathrm{C}$ to $350^{\circ} \mathrm{C}$ for 20 minutes and finally water quenched. Samples of both treatments were cut to analyze the transformation in bulk and to avoid surface effects such as decarburization. Etching in nital -2 pct was used for light optical observations.

\section{$\underline{\text { Results and Discussion }}$}

In order to determine the range of temperatures in which acicular ferrite develops, isothermal treatments at different temperatures between $600^{\circ} \mathrm{C}$ and $350^{\circ} \mathrm{C}$ were carried out. The resultant microstructures are presented in the micrographs of Fig. 1. A brief description indicating the microstructural constituents (poligonal ferrite, pearlite and/or acicular ferrite), and the mechanism of formation (reconstructive and/or displacive) for each of these microstructures can be seen in Table 2.

As it is shown in the micrograph of Fig. 1.a, the microstructure obtained at the highest temperature studied, $600^{\circ} \mathrm{C}$, comprises a mixture of two phases, ferrite and pearlite, both of which originated by the decomposition of the austenite following diffusion-controlled processes. The former can be observed covering the whole of the austenite grain boundaries as allotriomorphic ferrite and nucleating at inclusions inside the austenite grains as idiomorphic ferrite while the latter fills the rest of the austenite grain interiors. Although the microstructure at $550^{\circ} \mathrm{C}$ is similar to that obtained at $600^{\circ} \mathrm{C}$ some isolated ferrite plates are formed inside the austenite grains as can be seen in Fig. 1b. It has also to be noted that the thickness of the allotriomorphic ferrite layer on austenite grain boundaries is thinner at $550^{\circ} \mathrm{C}$ than in the previous case and that there are some boundaries where the formation of this layer has not taken place.

When the temperature is reduced to $500^{\circ} \mathrm{C}$, as it is presented in Fig. 1c, the microstructure reveals a transition between the ones corresponding to higher temperatures. The microstructure is mainly composed of poligonal ferrite and pearlite, with acicular ferrite, which is obtained at lower temperatures. In the same microstructure, phases characterised by a diffusional mechanism of growth, such as poligonal ferrite and pearlite, and plate shaped ferrite units probably originated following the same shear - difussional mechanism which controls the formation of bainitic plates can be seen (17-23). These plates, which are not enough to classify the microstructure as acicular ferrite, divide the original austenite grain into smaller carbon enriched regions where pearlite forms. In this way, the final microstructure is ferritic-perlitic but much finer than the one that would correspond to the grain size of the parent austenite.

Lowering the treatment temperature to $450^{\circ} \mathrm{C}$ results in a significant increase of the number of ferrite plates at the expense of poligonal ferrite and pearlite, and the resultant microstructure has a clearly acicular appearance, see Fig. 1.d. A remarkable characteristic of this microstructure is the total absence of grain boundary nucleation of bainite, as in the case of the grain boundary that goes between A and $\mathrm{A}^{\prime}$ in Fig. 1d, due to the high effectiveness of intragranular nucleation at the second phase particles of the austenitic matrix (13-16). If the temperature is further reduced to $400^{\circ} \mathrm{C}$ and $350^{\circ} \mathrm{C}$, Figs. $1 . e$ and 

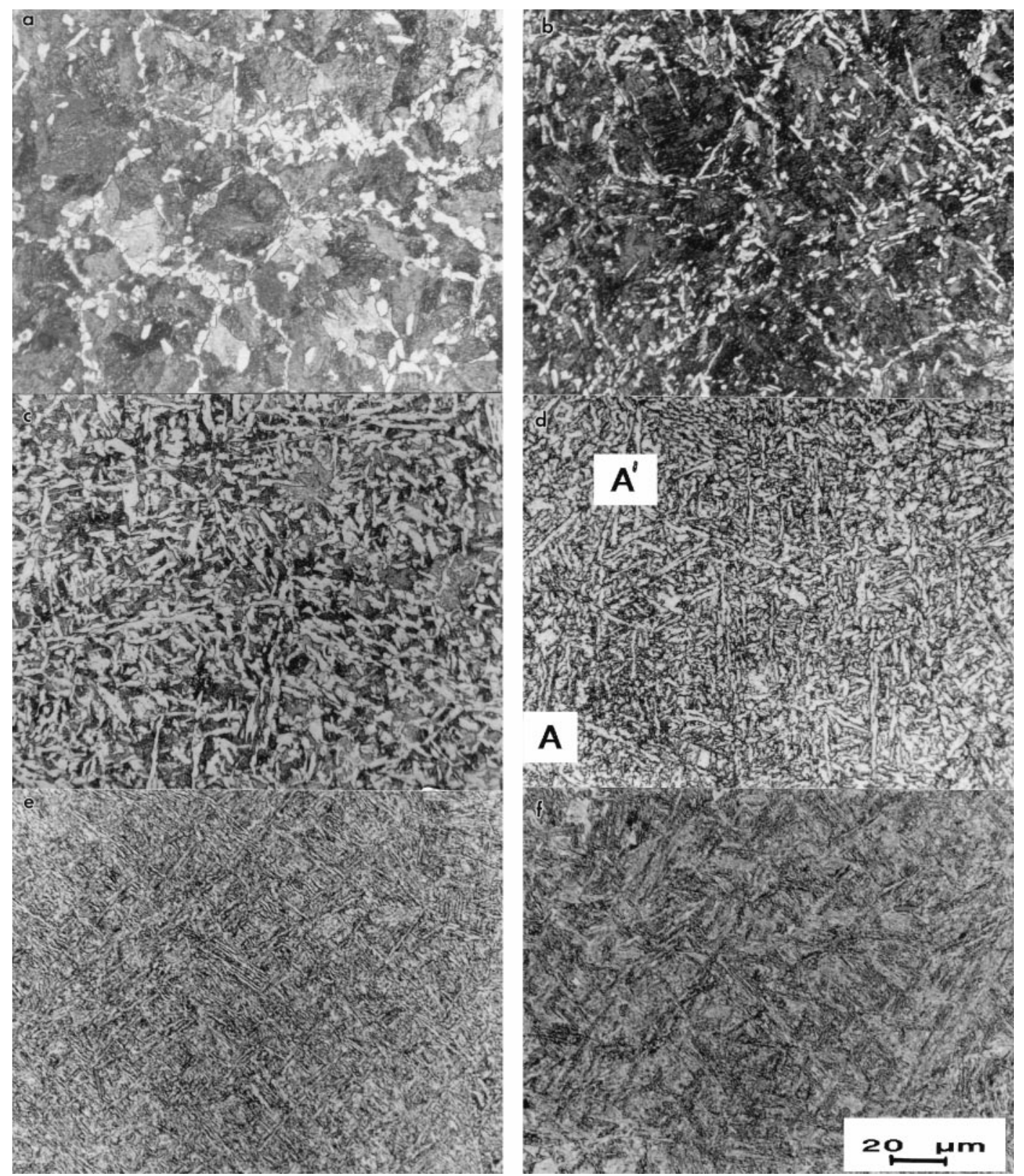

Figure 1. Microstructures obtained at different temperatures after full transformation of the austenite. $\mathbf{a} 600^{\circ} \mathrm{C}$. b $550^{\circ} \mathrm{C}$. c $500^{\circ} \mathrm{C}$. d $450^{\circ} \mathrm{C}$. e $400^{\circ} \mathrm{C}$. f $350^{\circ} \mathrm{C}$.

1.f, the ferrite presents the same plate morphology as in the previous case with a slight decrease in the thickness of the plates. However, in the treatment carried out at $450^{\circ} \mathrm{C}$ these plates are distributed in a chaotic manner with random orientations between them, at $400^{\circ} \mathrm{C}$ and $350^{\circ} \mathrm{C}$ they tend to align in parallel sheaves of ferrite that, in spite of looking like bainitic sheaves, have been intragranularly nucleated. The result is an acicular microstructure where the high disorientation and chaotic arrangement does not occur between individual ferrite plates but between these intragranular sheaves. 
TABLE 2

Characteristics of the Microstructures Obtained with Isothermal Treatments

\begin{tabular}{ccc}
\hline Treatment Temperature & Microstructural Description & Mechanism of growth \\
\hline $600^{\circ} \mathrm{C}$ & $\mathrm{P}, \mathrm{PF}$ & Reconstructive \\
$550^{\circ} \mathrm{C}$ & $\mathrm{P}, \mathrm{PF}$, Plates of ferrite $\downarrow$ & Reconstructive \\
$500^{\circ} \mathrm{C}$ & $\mathrm{P}$, Plates of ferrite, PF $\downarrow$ & Reconstructive, Displacive \\
$450^{\circ} \mathrm{C}$ & $\mathrm{AF}$ & Displacive \\
$400^{\circ} \mathrm{C}$ & $\mathrm{AF}$ (Sheaves of parallel plates) & Displacive \\
$350^{\circ} \mathrm{C}$ & $\mathrm{AF}$ (Sheaves of parallel plates) & Displacive \\
\hline
\end{tabular}

$\mathrm{AF}=$ Acicular ferrite, $\mathrm{P}=$ Pearlite, $\mathrm{PF}=$ Poligonal Ferrite (allotriomorphic + idiomorphic), $\downarrow=$ small volume fraction.

The analysis of the microstructures obtained with isothermal treatments has shown the need for using temperatures below $500^{\circ} \mathrm{C}$ to ensure a high volume fraction of acicular ferrite plates. As it has been previously commented, another striking feature of the acicular ferrite obtained at these temperatures is the almost total inhibition of grain boundary nucleation of bainite without the prior formation of an allotriomorphic ferrite layer. This behaviour rules out the requirement of high temperature isothermal treatments to promote the formation of this kind of layer and avoid bainite nucleation as proposed in a previous study (16). Taking this into account, the cooling rates necessary to reach the acicular ferrite formation range without the formation of other phases such as allotriomorphic ferrite or pearlite have to be determined.

The continuous cooling transformation (CCT) diagram after austenitization at $1200^{\circ} \mathrm{C}$ developed for this steel using dilatometric techniques is presented in Fig. 2. In this diagram PF is poligonal ferrite (allotriomorphic + idiomorphic), $\mathrm{P}$ is pearlite, $\mathrm{M}$ is martensite and $\mathrm{AF}$ is acicular ferrite or bainite (both phases grow with the same shear diffusional mechanism of growth).

The CCT diagram presented in Fig. 2 shows that the non-isothermal austenite-to-acicular ferrite transformation in this steel occurs at cooling rates ranging from $25^{\circ} \mathrm{C} / \mathrm{s}$ to $1{ }^{\circ} \mathrm{C} / \mathrm{s}$. However, a high volume fraction of acicular ferrite is only obtained at cooling rates between $10^{\circ} \mathrm{C} / \mathrm{s}$ and $1{ }^{\circ} \mathrm{C} / \mathrm{s}$, which are easily reproduced in an industrial scale. Cooling rates slower than $2^{\circ} \mathrm{C} / \mathrm{s}$ would promote the

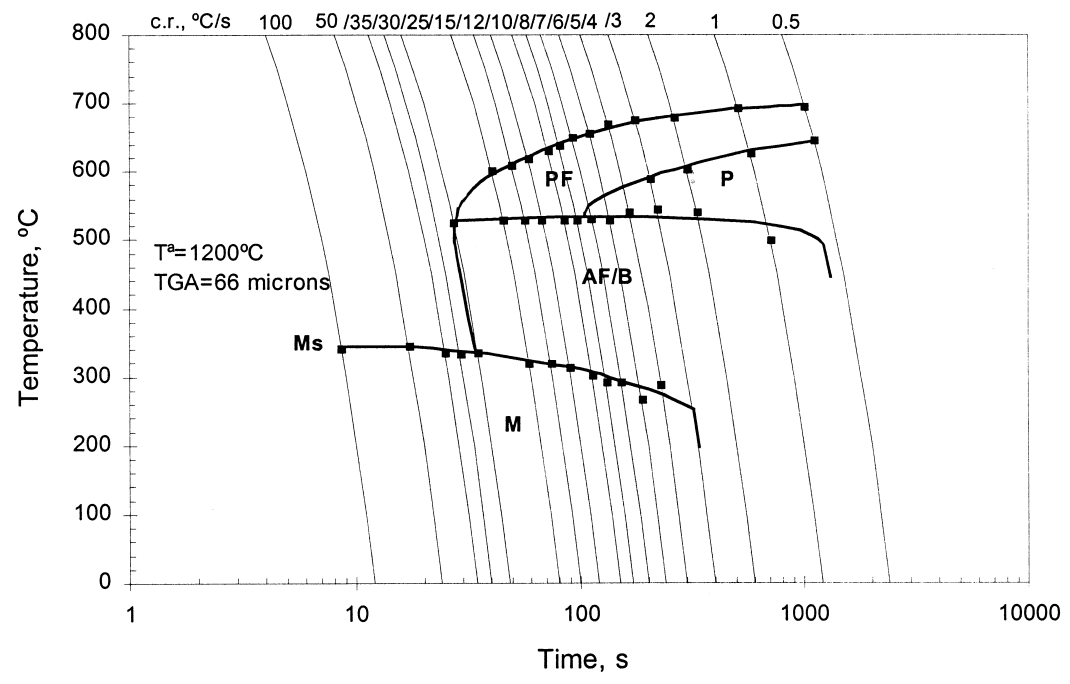

Figure 2. Continuous cooling transformation (CCT) diagram after austenitization at $1200^{\circ} \mathrm{C}$. 


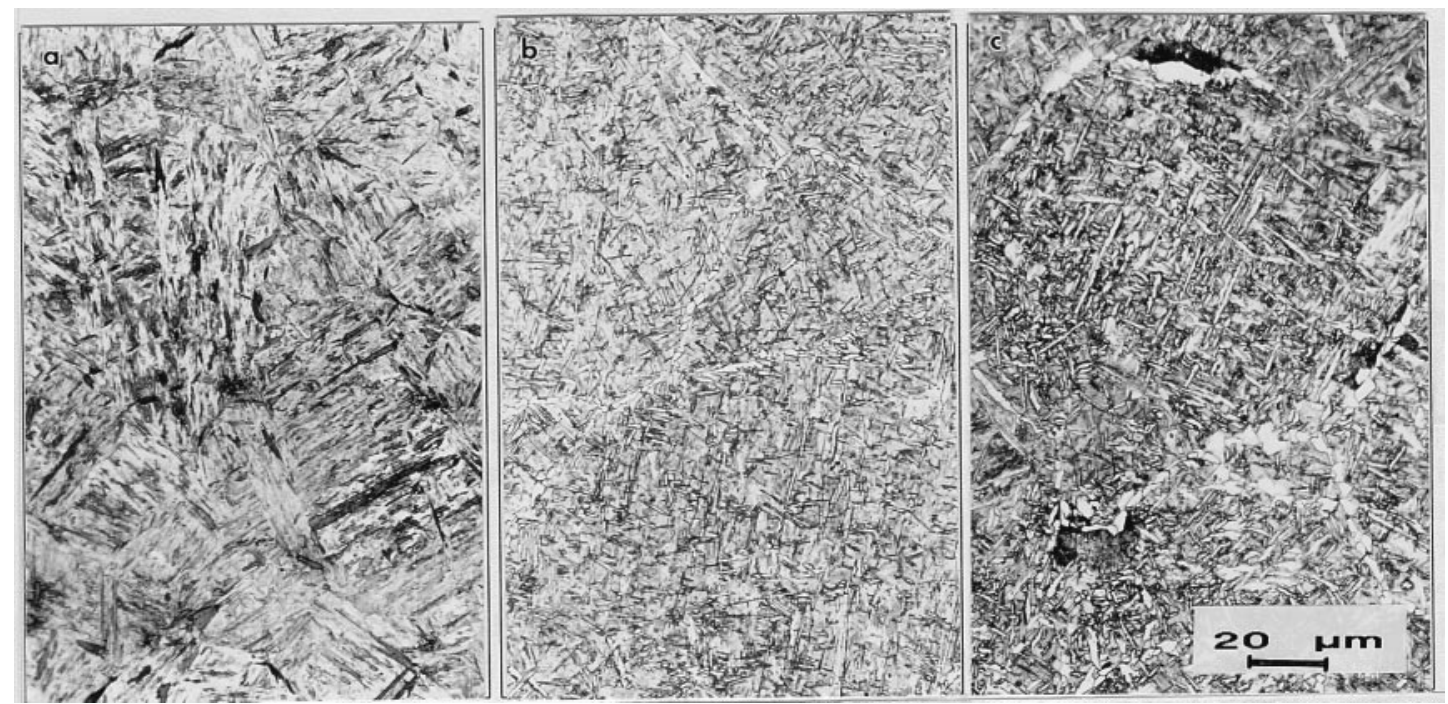

Figure 3. Microstructures obtained with continuous cooling to room temperature. a. $30^{\circ} \mathrm{C} / \mathrm{s}$. b. $10^{\circ} \mathrm{C} / \mathrm{s} . \mathbf{c} .6^{\circ} \mathrm{C} / \mathrm{s}$.

predominant formation of a mixture of pearlite and allotriomorphic ferrite. The former is avoided cooling down at about $7^{\circ} \mathrm{C} / \mathrm{s}$ and the latter is suppressed if cooling is carried out at $30^{\circ} \mathrm{C} / \mathrm{s}$. Nevertheless, as can be seen in the micrograph of Fig. 3.a, when the samples are continuously cooled down at $30^{\circ} \mathrm{C} / \mathrm{s}$, the obtained microstructure is martensite, which is not a desired phase due to its detrimental effect in toughness. Besides that, application of cooling rates higher than $10^{\circ} \mathrm{C} / \mathrm{s}$ is difficult in industrial processes. In many cases, these cooling rates have to be discarded for this reason, which has motivated the study of the acicular ferrite volume fractions that can be obtained with slower cooling rates despite the possible formation of allotriomorphic ferrite and pearlite.

The microstructure obtained if the cooling rate is reduced to $10^{\circ} \mathrm{C} / \mathrm{s}$ is presented in Fig. 3.b. As this figure shows, the formation of pearlite has been totally inhibited along the whole of the transformation but there is a fine layer of allotriomorphic ferrite which represents $7 \%$ of the microstructure and covers most of the austenite grains. However intragranular transformation of the austenite takes place, leading to the formation of acicular ferrite plates. The decomposition of the austenite is not completed before reaching the martensite start temperature, which causes the appearance of this phase at the end of the cooling. An analogous situation is obtained when the cooling rate is $6^{\circ} \mathrm{C} / \mathrm{s}$, as can be seen in Fig. 3.c. The only difference between both microstructures is a slight increase in the volume fraction of allotriomorphic ferrite $\left(10 \%\right.$ at $\left.6^{\circ} \mathrm{C} / \mathrm{s}\right)$, and the formation of some nucleus of pearlite which represent $2 \%$ of the microstructure. In the same way, the volume fraction of acicular ferrite is also increased at the expense of the volume fraction of martensite.

The results have shown that if the cooling rates required to avoid the formation of a high volume fraction of allotriomorphic ferrite and pearlite are maintained until room temperature, the development of martensite is inevitable. In the present case, this phase is not desired in the microstructure and, in order to elude its formation, the cooling rates have to be lowered after reaching the range of temperatures where acicular ferrite develops.

Micrographs of the isothermal treatments presented in Fig. 1 indicate that the formation of a great number of acicular ferrite plates takes place under $500^{\circ} \mathrm{C}$, which has motivated the choice of this temperature, below the acicular ferrite start temperature for all the cooling rates tested in the CCT, as the temperature where the cooling rate is lowered. The microstructure obtained when the first part of 

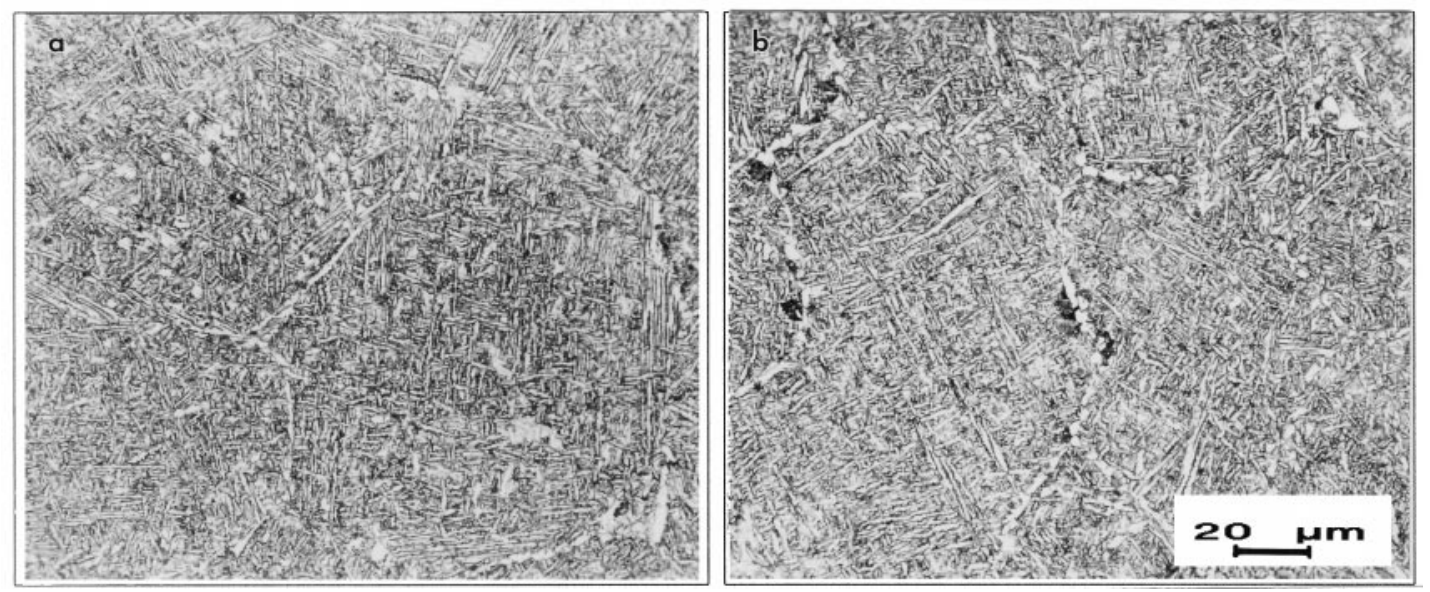

Figure 4. Microstructures obtained with two stage continuous cooling. a. $10^{\circ} \mathrm{C} / \mathrm{s}\left(1200^{\circ} \mathrm{C}\right.$ to $\left.500^{\circ} \mathrm{C}\right)$ and $2^{\circ} \mathrm{C} / \mathrm{s}\left(500^{\circ} \mathrm{C}\right.$ to room temperature). b. $6^{\circ} \mathrm{C} / \mathrm{s}\left(1200^{\circ} \mathrm{C}\right.$ to $\left.500^{\circ} \mathrm{C}\right)$ and $2^{\circ} \mathrm{C} / \mathrm{s}\left(500^{\circ} \mathrm{C}\right.$ to room temperature $)$.

the cooling (from $1200^{\circ} \mathrm{C}$ to $500^{\circ} \mathrm{C}$ ) is conducted at $10^{\circ} \mathrm{C} / \mathrm{s}$ and the subsequent cooling is carried out at $2^{\circ} \mathrm{C} / \mathrm{s}$ can be seen in Fig. 4.a. The micrograph reveals a high volume fraction of acicular ferrite which covers the whole of the austenite grain interiors with only a thin layer of allotriomorphic ferrite covering part of the austenite grain boundaries and representing $7 \%$ of the microstructure. If the first part of the cooling is performed at a lower cooling rate, $6^{\circ} \mathrm{C} / \mathrm{s}$, the decomposition of the austenite leads to the microstructure presented in Fig. 4.b. The acicular ferrite thus obtained is similar to the one attained in the preceding case but is slightly coarser due to the greater thickness of the ferrite plates. Another difference between the two microstructures is the increase of the amount of grain boundary ferrite and the appearance of some nuclei of pearlite when the cooling rate is reduced. The volume fractions of these phases are $10 \%$ for the allotriomorphic ferrite and $2 \%$ for the pearlite.

These last results clearly show that the formation of allotriomorphic ferite and pearlite is unavoidable when the cooling rate is less than $30^{\circ} \mathrm{C} / \mathrm{s}$ and $7^{\circ} \mathrm{C} / \mathrm{s}$, respectively. However, a high volume fraction of acicular ferrite can be obtained cooling at $10^{\circ} \mathrm{C} / \mathrm{s}(93 \%)$ and even at $6^{\circ} \mathrm{C} / \mathrm{s}(88 \%)$ and lowering these cooling rates after reaching to $500^{\circ} \mathrm{C}$.

\section{Conclusions}

1. Acicular ferrite has been obtained by both isothermal treatments and continuous coolings in a medium carbon microalloyed forging steel.

2. The observed inhibition of grain boundary nucleation of bainite enables the formation of fully acicular microstructures, although the high cooling rates $\left(30^{\circ} \mathrm{C} / \mathrm{s}\right)$ needed to completely avoid the formation of allotriomorphic ferrite reduce its industrial applicability.

3. Lower cooling rates cause the development of other phases such as allotriomorphic ferrite or pearlite but a high volume fraction of acicular ferrite can be achieved using two stage continuous cooling cycles.

\section{Acknowledgments}

Authors acknowledge financial support from the Spanish Comisión Interministerial de Ciencia y Tecnología (CICYT) (project-PETRI 95-0089-OP). GSB Acero S.A is thanked for providing the steel 
and their collaboration in this project. I. M. also whises to thank a 'Formación de Investigadores' grant from the Departamento de Educación y Universidades of the Gobierno Vasco.

\section{References}

1. D. J. Abson and R. E. Dolby, Weld. Inst. Res. Bull. 19, 202 (1987).

2. J. G. Garland and P. R. Kirkwood, Met. Constr. 7, 275 (1975).

3. J. G. Garland and P. R. Kirkwood, Met. Constr. 7, 320 (1975).

4. S. Ohkita, H. Homma, S. Tsushima, and N. Mori, in Conference Proceedings of the Joint Australian Welding and Testing Conference, Perth, Australian Welding Institute/Australian Institute NDT, p. 27.1 (1984).

5. F. J. Barbaro, P. Kraulis, and K. E. Easterling, Mat. Sci. Technol. 5, 1057 (1989).

6. J. M. Gregg and H. K. D. H. Bhadeshia, Acta Mater. 45, No. 2, 739 (1997).

7. M. A. Linaza, PhD Thesis, Facultad de Ciencias, Universidad de Navarra, San Sebastian (1994).

8. J. L. Romero, PhD Thesis, Escuela Superior de Ingenieros Industriales, Universidad de Navarra, San Sebastian (1996).

9. M. A. Linaza, J. L. Romero, J. M. Rodriguez-Ibabe, and J. J. Urcola, Scripta Metall. Mater. 29, 1217 (1993).

10. M. A. Linaza, J. L. Romero, J. M. Rodriguez-Ibabe, and J. J. Urcola, Scripta Metall. Mater. 32, 395 (1995).

11. J. L. Romero, M. A. Linaza, J. I. San Martin J. M. Rodriguez-Ibabe, and J. J. Urcola, Rev. Meta. (CENIM). 32, 1 (1996).

12. Y. Ito, M. Nakanishi, and Y. Komizo, Met. Constr. 14, 472 (1982).

13. I. Madariaga and I. Gutiérrez, Scripta Mater. 37, 1185 (1997).

14. I. Madariaga, J. L. Romero, and I. Gutiérrez, Metall. Trans. 29A, 1003 (1998).

15. I. Madariaga and I. Gutiérrez, Acta Metall. Accepted for publication.

16. C. García de Andrés, C. Capdevila, and F. G. Caballero, in TRATERMAT '98, ed. M. Carsí, F. Peñalba, O. A. Ruano, B. J. Fernández, p. 135, Madrid, Spain (1998).

17. H. K. D. H. Bhadeshia and D. V. Edmonds, Acta Metall. 28, 1265 (1980).

18. S. S. Babu and H. K. D. H. Bhadeshia, Mater. Sci. Eng. A156, 1 (1992).

19. F. J. Barbaro, P. Kraulis, and K. E. Easterling, Mater. Sci. Technol. 5, 1057 (1989).

20. H. K. D. H. Bhadeshia, Acta Metall. 29, 1117 (1981).

21. L. C. Chang and H. K. D. H. Bhadeshia, Mater. Sci. Technol. 12, 233 (1996).

22. J. R. Yang and H. K. D. H. Bhadeshia, Mater. Sci. Technol. 5, 93 (1989).

23. M. Strangwood and H. K. D. H. Bhadeshia, in Proceedings of the International Conference on Advances in Welding Science and Technology, p. 187, ASM, Cleveland, OH (1987). 